\title{
Genetic variation derived from natural gene flow between sympatric species in land snails (Mandarina)
}

\author{
SATOSHI CHIBA \\ Institute of Biology and Earth Science, Shizuoka University, 836 Oya, Shizuoka, 422 J apan
}

\begin{abstract}
The effects of introgression between two sympatric species on intraspecific genetic variation were studied in the land snail species Mandarina anijimana and M. mandarina on the island of Anijima. Allozyme analysis suggests that extensive introgression between this sympatric pair of species is occurring at several sites. In spite of this extensive gene flow, these species remain morphologically distinct. This suggests that distinctive sympatric forms can persist for long periods despite significant gene flow between them. Because there are no effective geographical barriers in the island, the geographical variation within species in allozyme frequencies shown here are mostly produced by geographical variation in the level of gene exchange between the two species. These breakdowns in reproductive isolation between species mostly occur in populations in the transitional zone between shrub and forest or at sites with poor vegetation. Mandarina anijimana is rare in the transitional zone and is never found in the forest, but alleles introduced from $M$. anijimana are found at high frequency in the populations of $M$. mandarina in these areas. This suggests 'frequency-dependent' hybridization in which the rare species at a site mates with individuals of the other sympatric species.
\end{abstract}

Keywords: allozymes, genetic variation, hybridization, land snail, Mandarina.

\section{Introduction}

The evolutionary potential of a species depends largely on the levels and patterns of genetic variation in its populations. Genetic variation is determined by the population dynamics, effective population size, the mating system and the historical pattern of interaction with other populations. Interactions between genetically different populations are particularly important in creating genetic variability within populations of organisms with geographically limited gene flow. Recent studies have suggested that the breakdown of reproductive isolation or incomplete isolation between sympatric species of animals is commoner than had been anticipated (Lehman et al., 1991; Grant \& Grant, 1992; Chiba, 1993; Dowling \& DeMarais, 1993; Falniowski et al., 1993; Byrne \& Anderson, 1994; for a review, see Harrison, 1993), and such hybridizations have significant effects on genetic variation.

Correspondence. E-mail: seschib@sci.shizuoka.ac.jp
Because of their limited mobility, land snails are often divided into genetically isolated populations occupying small areas, which often produce hybrid zones where they are in contact. They are regarded as excellent model systems for the study of population genetic structure (e.g. Clarke \& Murray, 1969; Clarke et al., 1978; Jones et al., 1980; Murray \& Clarke, 1980; Gould \& Woodruff, 1986, 1990; Woodruff, 1989; Johnson et al., 1993; Thomaz et al., 1996). In this study, allozyme variation is examined in the land snails Mandarina anijimana Chiba and $M$. mandarina Sowerby on the oceanic Bonin Islands. These species coexist on the island of Anijima and are morphologically distinct. Anijima is a very small (c. $8 \mathrm{~km}^{2}$ in area) and flat island with a relatively uniform environment, which acts as an excellent natural laboratory.

The goal of the present work was to clarify the effect of gene flow between two sympatric species. In this study, it is shown that an admixture of alleles can be produced by interspecific hybridization, and 
that such hybridization is an important source of genetic variation within species.

\section{Materials and methods}

\section{Study species and site}

Mandarina mandarina is found on Anijima and on Chichijima (located to the south of Anijima), but $M$. anijimana is endemic to Anijima. The vegetation of Anijima can be classified into shrub and forest as follows (Shimizu, 1989): shrub A, covered by poor vegetation with trees of less than $1 \mathrm{~m}$ and dominated by Distylium lepidotum; shrub B, covered by trees of less than $4 \mathrm{~m}$ and dominated by Distylium lepidotum and Schima mertensiana; forest C, covered by trees taller than $6 \mathrm{~m}$ and dominated by Pouteria obovata; forest $\mathrm{D}$, covered by trees taller than $5 \mathrm{~m}$ and dominated by Livistona chinensis; forest $\mathrm{E}$, disturbed coastal forest in which Mandarina is not found. The areas covered by shrub are drier than those covered by forest. Mandarina anijimana is restricted to shrub and never found in forest. Although M. mandarina is distributed in both shrub and forest, it is more abundant in the forests. In the areas with poor vegetation (shrub A), both species are very rare.

Sixteen samples of M. mandarina and 12 samples of $M$. anijimana were collected from 16 localities in Anijima (see Fig. 1 and Table 1). The specimens in each sample were adult snails taken from a quadrat $25 \mathrm{~m}^{2}$ in area. This is less than the average area of a

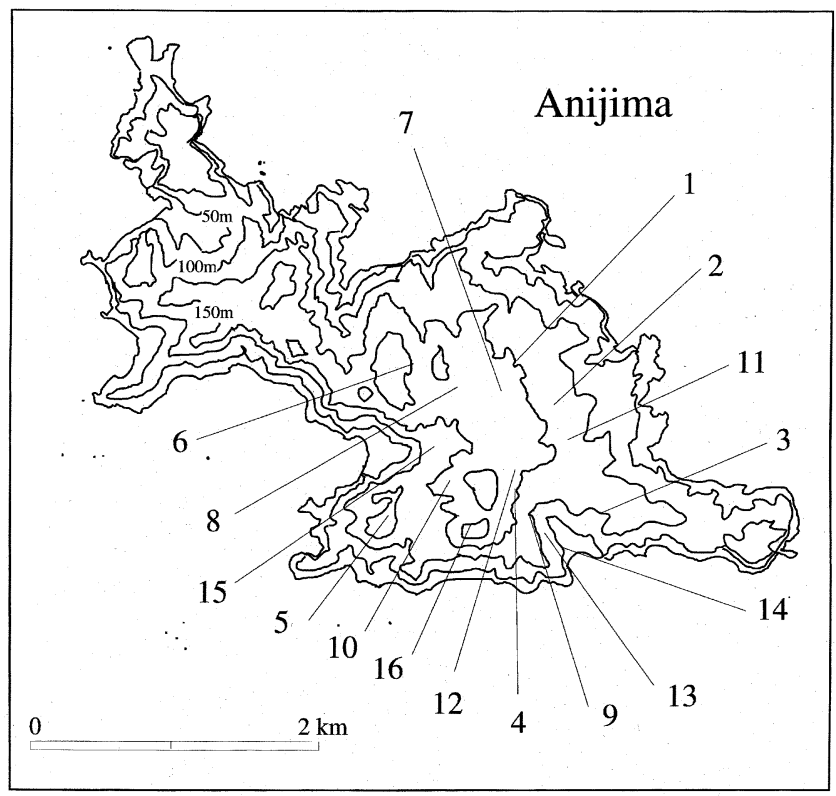

Fig. 1 Map of Anijima Island in the Bonin Islands, indicating locations of sampling sites. colony of these species. Between four and 28 snails were found in each collecting site. All adult snails in each quadrat were collected, and therefore the sample size reflected the density of the population in each collecting site. The identity of specimens of $M$. mandarina and $M$. anijimana was confirmed on the basis of genital morphology: the former has a large penis, cylindrical in shape, and a short, thick epiphallus with a relatively short flagellum, whereas the latter has a small, slender penis and a narrow, long epiphallus with a relatively long flagellum.

Mandarina anijimana has a shell with a clear umbilicus and bright yellow ground colour. Most of the specimens possess a narrow band just below the periphery and around the umbilicus. Sometimes, two additional bands appear on the uppermost and lower parts of the whorl, and specimens without any bands of colour are also found. Mandarina mandarina has a shell that is dark brown with a bright yellow line on the periphery and a pale brown band around the basal lip, and it does not have an umbilicus. Several specimens possess a pale brown shell with a bright yellow line on the periphery and two or four dark brown bands on the whorl (the one around the umbilicus is faint). These specimens have a colour pattern that is intermediate between the patterns of $M$. mandarina and $M$. anijimana. To examine the variation in shell morphology, the colour pattern and the presence or absence of an umbilicus were scored. The colour patterns were classified into three categories: score 0 for typical $M$. anijimana, score 2 for typical $M$. mandarina and score 1 for intermediates. The umbilicus was classified into three categories: a score of 0 was when it was clearly open, a score of 1 for when it was obscure and a score of 2 for a closed umbilicus.

\section{Enzyme electrophoresis}

The specimens were analysed by horizontal starch gel electrophoresis. The following 21 loci were scored in each individual: alkaline phosphatase (EC 3.1.3.1, locus $A l p$ ), aspartate aminotransferase (EC 2.6.1.1, locus Aat-1, Aat-2), catalase (EC 1.11.1.6, locus Cat), glucose-6-phosphate dehydrogenase (EC 1.1.1.49, locus G6pdh-1, G6pdh-2), glucose-6-phosphate isomerase (EC 5.3.1.9, locus Pgi), general protein $(G p)$, hexokinase (EC 2.7.1.1, locus $H k$ ), isocitrate dehydrogenase (EC 1.1.1.42, locus Idh), leucine aminopeptidase (EC 3.4.11.1, locus Lap-1, Lap-2), malate dehydrogenase (EC 1.1.1.37, locus $M d h$ ), malic enzyme (EC 1.1.1.40, locus $M e$ ), mannose-6-phosphate isomerase (EC 5.3.1.8, locus Mpi), phosphoglucomutase (EC 5.4.2.2, locus Pgm), 
6-phosphogluconate dehydrogenase (EC 1.1.1.44, locus 6pgd), sorbitol dehydrogenase (EC 1.1.1.14, locus Sordh), superoxide dismutase (EC 1.15.1.1, locus Sod-1, Sod-2) and xanthine dehydrogenase (EC 1.1.1.204, locus $X d h$ ). Alleles at each locus were denoted numerically by their relative anodal mobilities. These electrophoretic patterns were resolved using the staining technique of Hillis \& Moritz (1990). Further details of the electrophoretic survey are given in Chiba (1993).

For each sample, the allele frequencies and the heterozygosity $(H)$ were calculated. To test for deviations of genotype frequencies from HardyWeinberg expectations, $\chi^{2}$ tests were performed for the polymorphic loci. In addition, $F$-statistics
(Wright, 1978) were calculated to examine genetic differentiation within and between samples.

\section{Results}

Fourteen of the 21 loci (Aat-1, Aat-2, Alp, Cat, G6pdh-1, G6pdh-2, Gp, Hk, Mdh, 6pgd, Sod-1, Sod-2, Sordh and $X d h$ ) were monomorphic for the same allele in the two species. One locus, Pgi, had four alleles, and six loci, Idh, Lap-1, Lap-2, Me, Mpi and Pgm, had two alleles. Chi-squared tests for deviation from panmixia revealed no cases of significant departure from Hardy-Weinberg equilibrium $(P<0.05)$. The means and ranges of $F_{\mathrm{IS}}$ for all samples of each species are presented in Table 2.

Table 1 Sample size, vegetation of sampling site and frequency of variation of shell umbilicus and colour patterns in samples of Mandarina snails

\begin{tabular}{|c|c|c|c|c|c|c|c|c|}
\hline \multirow[b]{2}{*}{ Locality } & \multirow[b]{2}{*}{$n$} & \multirow[b]{2}{*}{ Vegetation } & \multicolumn{3}{|c|}{ Umbilicus } & \multicolumn{3}{|c|}{ Colour pattern } \\
\hline & & & 0 & 1 & 2 & 0 & 1 & 2 \\
\hline \multicolumn{9}{|c|}{ M. mandarina } \\
\hline 1 & 25 & $\mathrm{Sb}$ & - & - & 1.00 & - & - & 1.00 \\
\hline 2 & 20 & $\mathrm{Sb}$ & - & - & 1.00 & - & - & 1.00 \\
\hline 3 & 18 & $\mathrm{Sb}$ & - & - & 1.00 & - & - & 1.00 \\
\hline 4 & 27 & $\mathrm{Sb}$ & - & - & 1.00 & - & - & 1.00 \\
\hline 5 & 20 & $\mathrm{Sb}$ & - & - & 1.00 & - & - & 1.00 \\
\hline 6 & 25 & $\mathrm{Sb}$ & - & - & 1.00 & - & - & 1.00 \\
\hline 7 & 19 & $\mathrm{Sb}$ & - & - & 1.00 & - & - & 1.00 \\
\hline 8 & 25 & $\mathrm{Sb}-\mathrm{Fc}$ & - & - & 1.00 & - & - & 1.00 \\
\hline 9 & 16 & $\mathrm{Sb}-\mathrm{Fc}$ & - & 0.06 & 0.94 & - & 0.06 & 0.94 \\
\hline 10 & 8 & $\mathrm{Sa}$ & - & - & 1.00 & 0.13 & - & 0.87 \\
\hline 11 & 20 & $\mathrm{Sb}-\mathrm{Fc}$ & - & - & 1.00 & - & - & 1.00 \\
\hline 12 & 17 & $\mathrm{Fc}$ & - & - & 1.00 & - & - & 1.00 \\
\hline 13 & 27 & $\mathrm{Fc}$ & - & - & 1.00 & - & - & 1.00 \\
\hline 14 & 15 & $\mathrm{Fc}$ & - & - & 1.00 & - & - & 1.00 \\
\hline 15 & 14 & $\mathrm{Fc}$ & - & - & 1.00 & - & - & 1.00 \\
\hline 16 & 25 & $\mathrm{Fd}$ & - & - & 1.00 & - & - & 1.00 \\
\hline \multicolumn{9}{|c|}{ M. anijimana } \\
\hline 1 & 28 & $\mathrm{Sb}$ & 1.00 & - & - & 1.00 & - & - \\
\hline 2 & 22 & $\mathrm{Sb}$ & 1.00 & - & - & 1.00 & - & - \\
\hline 3 & 20 & $\mathrm{Sb}$ & 1.00 & - & - & 1.00 & - & - \\
\hline 4 & 23 & $\mathrm{Sb}$ & 1.00 & - & - & 1.00 & - & - \\
\hline 5 & 16 & $\mathrm{Sb}$ & 1.00 & - & - & 1.00 & - & - \\
\hline 6 & 24 & $\mathrm{Sb}$ & 1.00 & - & - & 1.00 & - & - \\
\hline 7 & 14 & $\mathrm{Sb}$ & 1.00 & - & - & 0.93 & 0.07 & - \\
\hline 8 & 11 & $\mathrm{Sb}-\mathrm{Fc}$ & 1.00 & - & - & 1.00 & - & - \\
\hline 9 & 7 & $\mathrm{Sb}-\mathrm{Fc}$ & 1.00 & - & - & 1.00 & - & - \\
\hline 10 & 12 & $\mathrm{Sa}$ & 1.00 & - & - & 0.92 & 0.08 & - \\
\hline 11 & 5 & $\mathrm{Sb}-\mathrm{Fc}$ & 0.80 & 0.20 & - & 1.00 & - & - \\
\hline 12 & 4 & $\mathrm{Fc}$ & 1.00 & - & - & 1.00 & - & - \\
\hline
\end{tabular}

$n$, sample size; Sa, shrub A; Sb, shrub B; Fc, forest C; Fd, forest D; Sb-Fc, transitional between forest $\mathrm{C}$ and shrub $\mathrm{B}$. 
Table 2 Summary of $F_{\mathrm{IS}}$ and $F_{\mathrm{ST}}$ for five loci in $M$. mandarina and $M$. anijimana

\begin{tabular}{lclcc}
\hline & \multicolumn{1}{c}{ M. mandarina } & \multicolumn{2}{c}{. anijimana } \\
Locus & $F_{\text {IS }}$ mean (range) & $F_{\mathrm{ST}}$ & $F_{\text {IS }}$ mean (range) & $F_{\mathrm{ST}}$ \\
\hline Pgi & $0.016(-0.22$ to 0.34$)$ & 0.029 & $-0.091(-0.091)$ & 0.077 \\
Me & $0.055(-0.097$ to 0.29$)$ & 0.24 & $0.013(-0.11$ to 0.25$)$ & 0.13 \\
Pgm & $-0.086(-0.11$ to -0.043$)$ & 0.028 & - & - \\
Lap-2 & $-0.053(-0.108$ to 0.055$)$ & 0.042 & $-0.053(-0.11$ to 0.070$)$ & 0.058 \\
Mpi & $0.011(-0.11$ to 0.42$)$ & 0.18 & $0.14(-0.11$ to 0.39$)$ & 0.22 \\
Lap-1 & $0.090(-0.16$ to 0.46$)$ & 0.026 & $0.043(-0.10$ to 0.33$)$ & 0.063 \\
\hline
\end{tabular}

The null hypothesis, that $F_{\text {IS }}$ equals zero, was tested by comparing $N\left(F_{\mathrm{IS}}\right)^{2}$ with a $\chi^{2}$ distribution $($ d.f. $=1)$. Significant positive $F_{\text {Is }}$-values $(P<0.05)$ were detected in two samples of M. mandarina at Lap-1 for Site 1 (0.46) and at Mpi for Site 13 (0.42). For all other sites and loci, however, no significant departure from the null expectation was found. These results, therefore, provide no significant evidence for inbreeding within the populations studied. The mean $F_{\text {IS }}$ (all polymorphic loci, all samples) of $M$. mandarina was 0.005 and that of $M$. anijimana was 0.011 , as a whole providing no evidence of departure from panmixia.

The geographical variation in allele frequencies at polymorphic loci in the two species shows that the populations of $M$. anijimana and $M$. mandarina at Sites 2-6 differed completely at four loci (Mpi, Lap-2, Me and Pgm), and marker alleles for M. anijimana $\left(\mathrm{Mpi}^{1.05}, \mathrm{Lap}-2^{0.96}, \mathrm{Me}^{1.08}, \mathrm{Pgm}^{0.9}\right)$ and for $\mathrm{M}$. mandarina $\left(\mathrm{Mpi}^{1.00}, \mathrm{Lap}-2^{1.00}, \mathrm{Me}^{1.15}, \mathrm{Pgm}^{1.0}\right)$ were identified (Fig. 2). In addition, two other alleles $\left(P g i^{1.3}\right.$ and $\left.P g i^{1.5}\right)$, which were found only in $M$. mandarina and at all sites except for 10 and 15 (Fig. 2 ), were also regarded as markers for $M$. mandarina. The two alleles Lap- $1^{1.0}$ and Lap- $1^{0.9}$, which occurred in both $M$. anijimana and $M$. mandarina, did not show fixed allelic differences at any site, and no meaningful geographical patterns were identified. $I d h^{1.0}$ was a common allele and fixed at most sites. A rare allele, $I d h^{1.2}$, was found at Sites 4 and 10 in $M$. anijimana at low frequency (0.04).

The populations of $M$. mandarina from Sites 1 and 7-12 possessed some of the marker alleles of $M$. anijimana, and the populations of $M$. anijimana from Sites 7 and 9-11 possessed some of the marker alleles of $M$. mandarina. In particular, the populations of $M$. mandarina from Sites 9, 10 and 11 had alleles of $M$. anijimana at high frequency. Most of these sites have poor vegetation (Site 10) or are in the transitional zone between shrub and forest (Sites 8, 9, 11 and 12). Populations of $M$. mandarina from the forest (Sites 13, 14 and 15) also possessed characteristic alleles of $M$. anijimana, but $M$. anijimana was not at these sites. There is a tendency for marker alleles of the other species to be present in populations from sites where the sample size of either or both of the two species are low. A geographical trend in the frequency of alleles along a transect from Site 14 to Site 4 shows that the frequencies of characteristic alleles of the other species are highest in the populations at the transitional zones between shrub and forest (Fig. 3).

The values for $F_{\mathrm{ST}}$ for each species show variations among loci. The low values of $F_{\mathrm{ST}}$ for Lap-1 (0.026-0.063) indicate that there are only small variations in allele frequencies at these loci among populations (Table 2). However, the values of $F_{\mathrm{ST}}$ for $M e$ and $M p i \quad(0.13-0.24)$ are far higher than those for Lap-1, indicating high levels of genetic variation among populations (Table 2).

Shells with intermediate colour patterns between $M$. mandarina and $M$. anijimana were found at several sites (Table 1). These intermediate specimens were not found in the populations that showed fixed allelic differences at the four allozyme loci. Shells with an obscure umbilicus were found in two sites, at each of which both species showed alleles characteristic of the other.

\section{Discussion}

The pattern of geographical variation in allozymes suggests gene flow between $M$. mandarina and $M$. anijimana. In earlier electrophoretic studies of Mandarina (Chiba, 1992, 1993, 1997), Mpi $i^{1.05}$, the marker allele of $M$. anijimana, is absent not only in populations of $M$. mandarina from Chichijima but also in all other species of Mandarina except for the nine populations of $M$. mandarina from Anijima. $\mathrm{Pgm}^{0.9}$ is also found in M. ponderosa from Hahajima island (located $50 \mathrm{~km}$ south of Chichijima), but this allele is never found in M. mandarina from Chichijima or any of the other species from islands around Anijima. Lap- $2^{0.96}$ and $M e^{1.08}$ are also found in $M$.

(c) The Genetical Society of Great Britain, Heredity, 80, 617-623. 
chichijimana, which is distributed in the southern areas of Chichijima and produces a hybrid zone with M. mandarina in the middle of the island. However, these alleles are not found in the pure populations of $M$. mandarina from northern areas of Chichijima (those nearest to Anijima). These results strongly suggest that the marker alleles of $M$. anijimana in populations of $M$. mandarina from Anijima have been introduced from $M$. anijimana. Although examination of variability in mitochondrial DNA would confirm this, it would seem that only through hybridization can the corresponding patterns at many loci and the finding of $M$. anijimana alleles in populations of $M$. mandarina from Anijima be explained.

Two alleles, $L a p-1^{0.97}$ and $L a p-1^{1.00}$, shared in $M$. anijimana and $M$. mandarina, are also found in the populations of $M$. mandarina from Chichijima. Therefore, interspecies gene flow will have little effect on the geographical variation of these alleles, relative to that of the marker alleles. The low values of $F_{\text {ST }}$ for Lap-1 (0.026-0.063), indicating low genetic heterogeneity among populations, suggest that genetic drift and natural selection, by themselves, create little geographical variation in these populations of $M$. mandarina and $M$. anijimana. The high values of $F_{\mathrm{ST}}$ for $M p i$ and $M e(0.13-0.24)$ therefore indicate geographical variation in allozyme frequencies that arises mainly from gene exchange between the two species. Because of the small area of the island, fixation of alleles by genetic drift (or natural selection) is likely. This will often result in fixed allelic differences at particular loci between the sympatric pair of species. Occasional gene flow
Fig. 2 Geographical variation of the marker alleles. Frequencies of each allele at the loci Pgi, Pgm, Me, Lap-2 and $M p i$ are indicated by circles on the left of the axis for M. anijimana and on the right of the axis for $M$. mandarina. The numbers on each map refer to localities. Differences in the vegetation of the island are also shown on the map (see Table 1 and text). The areas without shading indicate areas without vegetation.

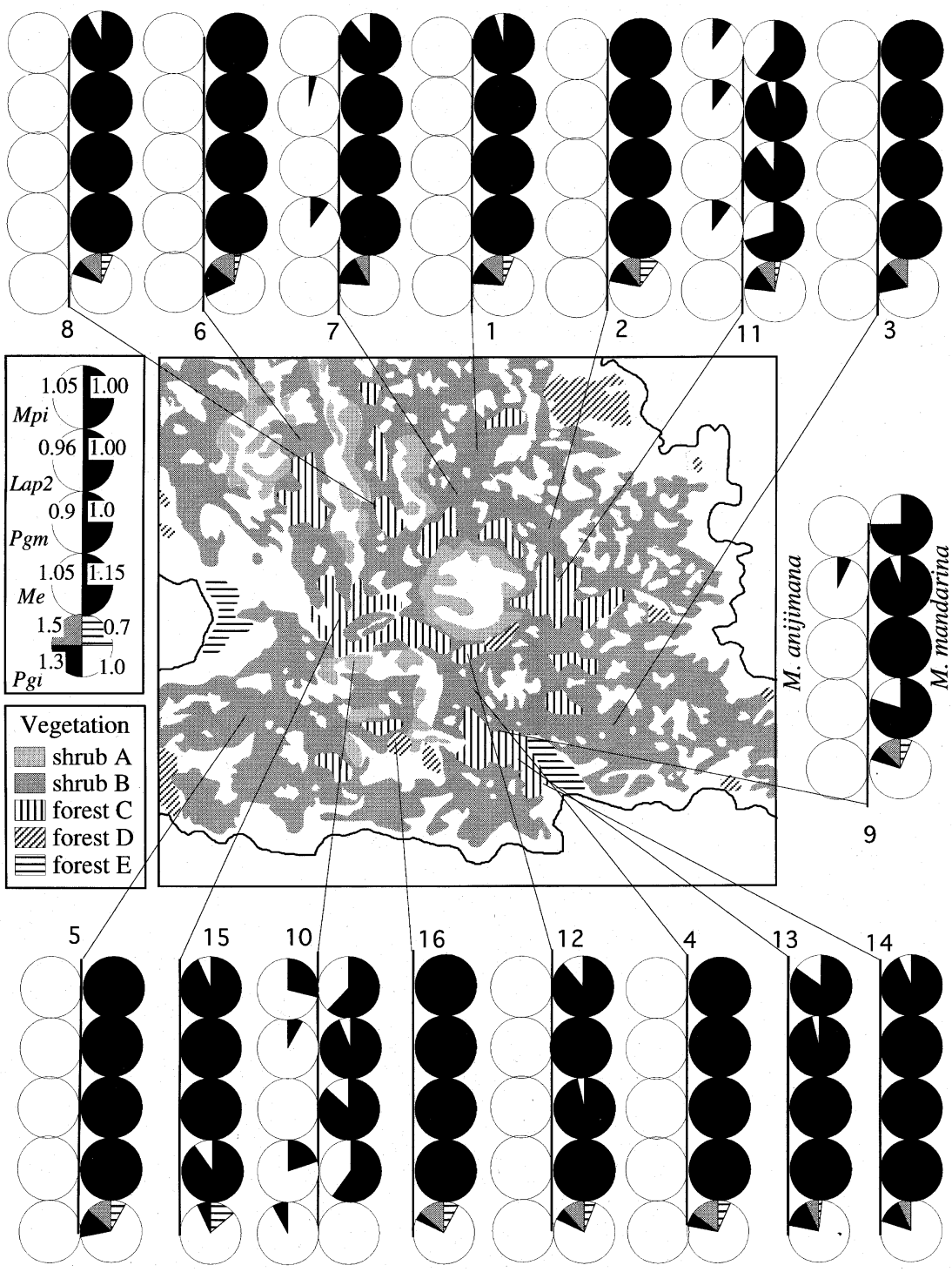




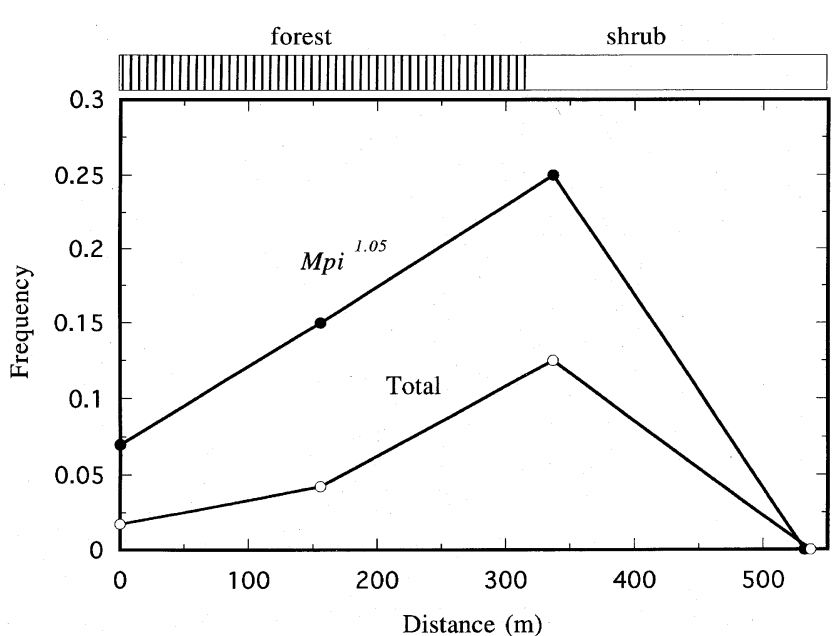

Fig. 3 Geographical trends in the frequency of $M p i^{1.05}$ and the average of the frequency of the marker alleles of $M$. anijimana in the populations of $M$. mandarina for samples along a transect from Site 14 to Site 3 . Values of these frequencies are plotted against the distance of each sample site from Site 14. Samples are from left to right: 14, 13, 9 and 4 .

between the species thus increases the genetic variability within each species.

The rate of gene flow between sympatric pairs of two species can be measured by $\left(q_{\mathrm{h}}-q_{0}\right) /\left(q_{\mathrm{p}}-q_{0}\right)$, where $q_{\mathrm{p}}$ is the frequency of a marker allele in one species at a particular locus in a pure population, $q_{0}$ is the frequency of a marker allele in the other species in the pure population and $q_{h}$ is a frequency of the marker allele of the other species in the hybrid population (Nei, 1987). High levels of interspecies gene flow (range 5-40\%) are found in the populations at Sites 8, 9 and 11, which are in transitional zones between forest and shrub. This suggests that some ecological factors are operating to create partial breakdown of reproductive isolation. One plausible scenario is 'frequency-dependent' hybridization. If one species is rare at a given site and an individual cannot find a conspecific partner to mate with, it may mate with individuals of the other sympatric species (Bauer, 1957; Lehman et al., 1991; Grant \& Grant, 1992). This hypothesis seems to be supported by the fact that hybrids were found at high frequencies in the transitional zone (Fig. 3), where $M$. anijimana becomes rare but $M$. mandarina is abundant. The presence of high levels of gene flow $(6-38 \%)$ between the species in populations from the poorly vegetated area (Site 10), where both species are rare (Fig. 2), also supports this hypothesis. Marker alleles of M. anijimana are found in populations of $M$. mandarina collected from the forest, where $M$. anijimana is not found. This implies that introduced alleles from $M$. anijimana flow into the forest populations from the transitional zone, where the hybridization occurs.

The presence of morphological intermediates (shells with obscure umbilicus and colour patterns intermediate between the two species) also supports the hypothesis of interspecific hybridization. Although land snails are notorious for their intraspecific plasticity in shell morphology, specimens of M. mandarina with an umbilicus must result from hybridization, because no specimens of this kind are ever found in the M. mandarina from Chichijima. In addition, colour patterns with mixtures of the typical patterns of the different species are characteristic of interspecies hybrids in Mandarina (Chiba, 1993, 1997). Despite the significant levels of gene exchange between the two species, however, most populations include no morphological intermediates. This suggests that selection operates against snails with intermediate morphology. Possibly, distinctive sympatric forms may persist for long periods, despite significant gene flow between them.

The exact mechanism of reproductive isolation between $M$. anijimana and M. mandarina is not clear at present. However, it may be a premating isolation, resulting from a simple ecological difference. The species have different microhabitat preferences: $M$. anijimana prefers relatively dry sites and $M$. mandarina relatively wet sites (Chiba, 1992). A similar case of reproductive isolation through simple ecological differences was found in the land snails Partula (Johnson et al., 1977; Murray et al., 1982). This kind of isolation could be broken easily, and fertile offspring might be produced.

The alteration of environmental conditions through human influence, with hybridization, resulting from this habitat change, has been reported in several animals (McDonnell et al., 1978; Harrison \& Arnold, 1982; Hillis, 1988). However, the hybridization between $M$. anijimana and $M$. mandarina cannot be a result of human activity, because there are no records of human colonization on Anijima. This suggests that natural gene flow between sympatric species may provide an additional source of genetic variability that is easily lost in waif biota.

\section{Acknow ledgements}

I am grateful to Drs I. Hayami and K. Tanabe for their helpful suggestions, and to Dr K. Tomiyama for providing information about Mandarina and the flora of Anijima island.

(C) The Genetical Society of Great Britain, Heredity, 80, 617-623. 


\section{References}

BAUER, к. 1957. Zur Systematischen Stellung des Blutspechtes. Johann Friedrich Naumann-Ehrung. Deutscher Kulturbund, Berlin.

BYRNE, M. AND ANDERSON, M. J. 1994. Hybridization of sympatric Patiriella species (Echinodermata: Asteroida) in New South Wales. Evolution, 48, 564-576.

CHIBA, s. 1992. Land snails Mandarina in the Bonin Islands. Kagaku, 62, 696-704 (in Japanese).

CHIBA, s. 1993. Modern and historical evidence for natural hybridization between sympatric species in Mandarina (Pulmonata: Camaenidae). Evolution, 47, 1539-1556.

CHIBA, s. 1997. Novel colour polymorphisms in a hybrid zone of Mandarina (Gastropoda: Pulmonata). Biol. J. Linn. Soc., 61, 369-384.

ClARKe, B. AND MURRAY, J. 1969. Ecological genetics and speciation in land snails of the genus Partula. Biol. J. Linn. Soc., 1, 31-42.

CLARKE, B., ARTHUR, W., HORSLEY, D. T. AND PARKIN, D. T. 1978. Genetic variation and natural selection in pulmonate molluscs. In: Fretter, V. and Peake, J. (eds) Pulmonates, Vol. 2A, pp. 219-270. Academic Press, London.

DOWLING, T. E. AND DEMARAIS, B. D. 1993. Evolutionary significance of introgressive hybridization in cyprinid fishes. Nature, 362, 444-446.

FALNIOWSKI, A., KOZIK, A. AND SZAROwsKa, M. 1993. Two common European viviparid species hybridize. Am. Malac. Bull., 10, 161-164.

GOULD, s. J. AND WOODRUFF, D. s. 1986. Evolution and systematics of Cerion (Mollusca: Pulmonata) on New Providence Island: a radical revision. Bull. Am. Mus. Nat. Hist., 182, 389-490.

GOULD, S. J. AND WOODRUFF, D. S. 1990. History as a cause of area effects: an illustration from Cerion on Great Inagua, Bahamas. Biol. J. Linn. Soc., 40, 67-98.

GRANT, P. R. AND GRANT, B. R. 1992. Hybridization of bird species. Science, 256, 193-197.

HARRISON, R. G. 1993. Hybrids and hybrid zones: historical perspective. In: Harrison R. G. (ed.) Hybrid Zones and the Evolutionary Process, pp. 3-12. Oxford University Press, New York.

HARRISON, R. G. AND ARNOLD, J. 1982. A narrow hybrid zone between closely related cricket species. Evolution, 36, 535-552.
HILlis, D. M. 1988. Systematics of the Rana pipiens complex: puzzle and paradigm. Ann. Rev. Ecol. Syst., 19, 39-63.

HILlis, D. M. AND MORITZ, C. 1990. Molecular Systematics. Sinauer Associates, Sunderland, MA.

JOHNSON, M. S., CLARKE, B. AND MURRAY, J. 1977. Genetic variation and reproductive isolation in Partula. Evolution, 31, 116-126.

JOHNSON, M. S., MURRAY, J. AND ClARKE, B. 1993. The ecological genetics and adaptive radiation of Partula on Moorea. In: Futuyma, D. and Antonovics, J. (eds) Oxford Surveys in Evolutionary Biology, Vol. 9, pp. 232-238. Oxford University Press, Oxford.

JONES, J. S., SELANDER, R. K. AND SCHNELL, G. D. 1980. Patterns of morphological and molecular polymorphism in the land snail Cepaea nemoralis. Biol. J. Linn. Soc., 14, 359-387.

LEHMAN, N., EISENHAWER, A., HANSEN, K., MECH, L. D., PETERSON, R. O., GOGAN, P. J. P. ET AL. 1991. Introgression of coyote mitochondrial DNA into sympatric North American gray wolf populations. Evolution, 45, 104-119.

MCDONNEll, L. J., GARTSIDE, D. F. AND LitTLEJOHN, M. J. 1978. Analysis of a narrow hybrid zone between two species of Pseudophryne (Anura: Leptodactylidae) in south-eastern Australia. Evolution, 32, 602-612.

MURRAY, J. AND ClARKe, B. 1980. The genus Partula on Moorea: speciation in progress. Proc. R. Soc. B, 211, 83-117.

MURRAY, J., JOHNSON, M. S. AND CLARKE, B. 1982. Microhabitat differences among genetically similar species of Partula. Evolution, 36, 316-325.

NEI, M. 1987. Molecular Evolutionary Genetics. Columbia University Press, New York.

SHImizu, y. 1989. Dry forest and endemic plants in Anijima, Bonin Islands. Bull. Ogasawara Res., 13, 7-19.

thomaz, D., Guiller, A. AND ClARKE, B. 1996. Extreme divergence of mitochondrial DNA within species of pulmonate land snails. Proc. R. Soc. B, 263, 363-368.

wOODRUFF, D. s. 1989. Genetic anomalies associated with Cerion hybrid zones: the origin and maintenance of new electromorphic variants called hybrizymes. Biol. J. Linn. Soc., 36, 291-294.

Wright, s. 1978. Evolution and the Genetics of Populations, Vol. 4, Variability Within and Among Natural Populations. University of Chicago Press, Chicago. 